\title{
Capstone Experiences: Effects of Adapted Physical Activity Design Projects on Attitudes and Learning
}

\author{
David W. Hey, Bridie Jean McCarey, Lynne A. Slivovsky, J. Kevin Taylor, Brian Self, and James Widmann
}

\begin{abstract}
Eight innovative senior level capstone engineering projects were completed at California Polytechnic State University (2008-present) involving $(n=28)$ students (23 male/5 female). All projects involved the design of equipment to facilitate physical activity for people with disabilities. The effects on: i) learning design, ii) attitude towards people with disabilities, and iii) motivation to complete team design projects were analyzed through eight one-hour focus groups. This paper presents focus group findings using a constructivist approach and grounded theory to explore the overall student "learn by doing" experience. Results: (1) Approximately 19 (70\%) of the students claimed the adapted physical activity project was their "first choice" given 60+ projects to rank; (2) Prior to the project only ten $(35 \%)$ had experience working with people with disabilities and of those students the majority were women; (3) Twenty-six (92.8\%) of the students were able to define 'inclusion' when asked and viewed the field of engineering as a 'natural fit' with project design for adapted physical activity. Students reported high levels of motivation for learning design as evidenced by the majority of engineers getting their "top" choice of projects; (4) Twenty-three (82\%) of the engineers would 'definitely' consider a future engineering job in this sector and (5) Project challenges included: budget constraints, group communication, fabrication delays, detachment from client, and a desire for increased product testing time. Although students reported high levels of learning and motivation to complete their project; attitudes toward people with disabilities did not change significantly.
\end{abstract}

Index Terms - Adapted physical activity, University, Disability, Engineering, Senior project

\section{INTRODUCTION}

One of the key elements of undergraduate engineering education is 'design' which is a fundamental skill acquired by all engineering students during their undergraduate years [1]. Engineering experience acquired in the senior design course is considered critical to students as they learn how to apply theory to an actual design project [2]. Engineering design is an often iterative process that consists of devising a system, component, or process to attain a desired need. An effective capstone design experience should help students develop a variety of abilities that are difficult to attain in typical laboratories. Program outcomes involved in senior level design reinforced by the Accreditation Board for Engineering and Technology (ABET) include the ability to [3]: 1) function on a multidisciplinary team; 2) communicate effectively; 3) design and conduct experiments; 4) analyze and interpret data; and 5) design a system that is within realistic constraints, etc. To be most effective, design projects require significant faculty involvement, and from the student's point of view, projects need to be challenging but not overwhelming. A fine motivational balance is required so that students can quickly become self-sufficient as they get up to speed on the technical details of the project and not get overwhelmed. This balance requires the faculty advisor to work closely with each group and client as project specifications are determined [4].

\section{Practical Applications}

People with disabilities constitute a minority group within society and as such are stigmatized in a similar way to other social minority groups [5]. Associated with the stigma of being disabled many people with disabilities can become marginalized through prejudice, stereotyping, and discrimination. An engineering student's attitudes, beliefs and opinions, including those about people with disabilities, may influence career choices but, more importantly, could have lasting impact on design decisions and inclusiveness throughout one's career. Engineers are problem solvers with a unique skill set of being able to provide everyone (regardless of need or ability) with a high quality of life. Additionally, engineers have the knowledge and capacity to design and build recreational equipment for people with disabilities. Functional end products have the potential to greatly enhance the quality of life for those individuals with disabilities who utilize the equipment. This opportunity offers a possible alternative to the conventional industry route for new engineers. Measuring and evaluating the experience in their senior project is paramount for interested parties to continue with such critically needed experiential projects.

\section{Matching Research Method with Research Aims}

The application of focus groups can help not only in explaining student attitudes (i.e., favorable towards people with disabilities etc.) and behavior (e.g., ultimately choosing an engineering profession to provide people with disabilities 
further recreational opportunities for more independence -or the least restrictive environment), but also in aiding to design a more effective senior project experience. The results of focus group research in this context may inform changes to course outlines, rules, communication expectations, etc. will satisfy their educational requirement and provide students with the best possible "learn by doing" student experience.

\section{Qualitative Focus Group Methodology as Research}

Focus groups are exploratory forms of qualitative research. One of the important purposes of this type of research is to utilize the "needs" and "capacity assessments" the focus group method provides and engage in brainstorming and generate ideas around a problem [6]-[7]. Its use has a short but rich history in engineering education research and has proven valuable to address questions, such as ours, for which quantitative methods are insufficient [8]-[10]. The focus group is typically an exploratory process that is used for generating hypotheses, uncovering attitudes and opinions, and acquiring and testing new ideas [11]-[13].

\section{PuRpose}

The purpose of this study was to gain greater insight into the effects of completing an adapted physical activity design project on: learning mechanical design, attitudes toward people with disabilities, and motivation to complete a project. More specifically, our goal was to identify student perceived benefits and barriers related to working with a multidisciplinary team comprised of Mechanical Engineering students and Kinesiology students. Researchers were most interested in the salient characteristics of the Engineer-Kinesiology working relationship; as two Kinesiology students were assigned to each engineering team to communicate anthropometric data on each client, and help with design and fabrication alterations as needed.

\section{Research Question}

What impact does completing a capstone engineering project in the design of recreational equipment for people with disabilities have on learning design and the motivation to complete such a project?

\section{Secondary Aims}

a. To evaluate impact or overall value of the project,

b. To evaluate process or student collaboration between engineering and kinesiology departments,

c. To evaluate and improve the existing program by adopting student ideas and reinforce the success of the program experience for future students, and

d. To understand if engineering students participating in this project value the experience and confirm the necessity of such a program. e. To evaluate worth or determine if students will consider a future profession in this engineering sector of the recreation industry.

\section{METHODS}

This study, as part of a larger study funded by the National Science Foundation, draws from the qualitative framework or paradigm of evaluation research. Constructivism utilizing grounded theory is based on the belief where the world is treated as a product of social interaction which can be observed and described [14]. There is increasing acknowledgment of the value of qualitative research by public health professionals and others engaged in multidisciplinary health-related research [15]-[17].

Prior to implementation, the protocol for this study was approved by the University's Institutional Review Board (IRB). Focus group questions were designed to: (1) determine if the project was among their first choice of projects from those on offer, (2) explore if their perceptions (i.e., attitudes, beliefs, and knowledge) of people with disabilities changed as a result of their capstone experience, (3) identify specific design concepts or design processes learned, (4) identify any academic and project design barriers, (5) determine if students could correctly identify the natural connection between 'engineering' and 'inclusion', (6) assess if students felt compelled to consider working with people with disabilities as a career, and (7) identify specific areas for improving the overall learning experience for future Engineering and Kinesiology students.

\section{Site}

Data were collected at a large, four-year public university located on the Central Coast of California. The campus can best be described as a comprehensive undergraduate education combining technical and professional curricula with the arts and the humanities.

\section{Participants}

To understand the academic and social experiences of men and women in engineering, engineering students enrolled in senior project and assigned to one of eight adapted design projects were purposefully selected $(n=28)$ to one of eight design projects. All projects had the intent promoting inclusion for people with disabilities in a specific physical activity. Projects included: a Hand and Foot Powered Cycle; a golf attachment for a Universal Play Frame; an inclusive court game called Foam Wars; an adaption to a Nintendo Wii system, Wii-B-Fit; a mobile standing frame called a Strider; a Sit and Ski; an adapted Paddling Launch Vehicle (APLV); and a second iteration of the hand and foot powered cycle, named "Quadricycle" (Table 1). Criterion sampling was used (i.e., assigned individuals to a given project were selected to attend a $\sim$ one hour team focus group at the end of their 9 month capstone project. Eight 
focus groups were conducted from spring 2009 to winter 2011 with 28 participants (23 male / 5 female).

TABLE I

DESIGN PROJECT AND STUDENT ENGINEERS

\begin{tabular}{lllll}
\hline $\begin{array}{l}\text { Project } \\
\text { No. }\end{array}$ & Project Title & Male & Female & $1^{\text {st }}$ Choice? \\
\hline 1 & Hand Foot Powered Cycle & 4 & 0 & 2 \\
2 & Universal Play Frame Golf & 1 & 2 & 2 \\
3 & Foam Wars & 3 & 0 & 1 \\
4 & Wii-B-Fit & 3 & 1 & 4 \\
5 & Strider & 3 & 0 & 1 \\
6 & Sit and Ski & 3 & 0 & 1 \\
7 & APLV & 3 & 1 & 2 \\
8 & Quadricycle & 3 & 1 & 4 \\
\multirow{2}{*}{ Total } & & 23 & 5 & 19 \\
& & & & \\
\end{tabular}

\section{Data Collection}

The focus group discussion followed a protocol based on a semi-structured interview guide, which was developed in accordance with established guidelines [18]-[19]. The interview guide, which consisted of a checklist of topics, prepared by the moderator, was discussed with the members of the research team and revised according to their comments.

\section{Data Analysis}

After each interview, first impressions from each session were discussed and written down by the moderator and two note takers. The data analysis process on transcripts began within 24 hours once the audio recording was transcribed and after the moderators and note takers completed debriefing reports. These reports covered the logistics of the space, the group dynamics, the moderators' performance, the participants' comprehension, emerging themes and unanticipated findings [20]. The data analysis process for this study was guided by the principles of grounded theory [21]. Grounded theory is particularly well suited to the analysis of this data in that the goal was to understand the issues that could serve as barriers or assets to the development of an experiential "learn by doing" project.

\section{Coding and Agreement}

Because of potential confidentiality issues with respondent validation and time demands this study utilized several other methods of data analysis to ensure the rigor of the evaluation research [22]. To ensure reliability, the analysis process involved three coders (all from the Kinesiology Department) who read the transcripts and independently wrote a summary of the main issues that emerged for each of the domains. Coders then were instructed to first make notes in the margins as to the main points and, thereafter, identified the main themes as understood by them for each of the questions. After coders developed these summaries independently, coders met to discuss the emerging themes.
Coders then reached a consensus on the main themes and sub-themes (see Table II). According to previous research, inter-coder agreement must be 0.90 or greater yet, and 0.70 is considered acceptable for most exploratory studies [23]. If and when different interpretations arose, coders had extensive discussions until an agreed upon final interpretation was established. Inter-rater reliability between the lead author and two coders were 0.89 and 0.93 . No computer software was utilized in the data analysis.

\section{FINDINGS}

TABLE II

EMERGENT THEMES FROM FOCUS GROUPS $(n=8)$

\begin{tabular}{ll}
\hline Major Themes & \multicolumn{1}{l}{ Sub Themes } \\
\hline 1. Learning Design & $\begin{array}{l}\text { a) Planning and Scheduling } \\
\text { b) Fabrication } \\
\text { c) Budgeting }\end{array}$ \\
$\begin{array}{ll}\text { 2. Motivation to } \\
\text { complete design }\end{array}$ & $\begin{array}{l}\text { a) Finishing a design } \\
\text { b) Working on real world design } \\
\text { c) Completing design from start to finish }\end{array}$ \\
$\begin{array}{ll}\text { 3. Perceptions of people } & \text { a) Previous experience } \\
\text { with disabilities } & \text { b) Changed attitudes } \\
\text { c. Planning stages } & \text { a) Changed beliefs }\end{array}$ \\
$\begin{array}{ll}\text { 5. Improving future } & \text { a) Communication between disciplines } \\
\text { projects } & \text { b) Meet client early and often } \\
& \text { c) Clarify expectations and tasks }\end{array}$
\end{tabular}

Inter-rater reliability $=0.89$ and 0.93

For a senior engineering design project to have maximum benefits for learning and motivation to learn, the following seven criteria should be met [3]. 1) multidisciplinary broad projects make students stretch 2) complete system not a component of the whole, 3) low cost, 4) real environment, 5) divisible e.g., each student has portion of common overall system 6) measureable e.g., clear grading criteria set as benchmarks towards progress to completion, and 7) adaptable e.g., flexible platform so project idea can be used over multiple years. In the remaining sections, these seven criteria are referenced to demonstrate student learning and motivation to learn design.

\section{Theme 1. Learning Design: a) Planning and Scheduling}

Communication is an important issue to address early in the project. Channels need to be established allowing for more open and frequent exchange of information. Primary contacts need to be recognized and regular status meetings scheduled. The potential for project difficulties, barriers and delays caused by poor communication was experienced by some.

Wii-B-Fit (2010)

"I'd think the Kinesiology student working with us has been doing a great job especially the last few weeks... but early 
on in the quarter it would be cool to get more involvement and more help scheduling things.”

\section{APLV (2009)}

"We had really good Kinesiology students we were working with. They were on top of things. The communication doesn't need to be improved."

Strider (2010)

"None of us had manufacturing experience and things took longer than expected. Towards the end we felt like they (Kinesiology students) were being pushy and the initial deadlines flew by."

Example of understanding the important issues before beginning the design process students must understand the physiological limitations, in this case the extent of the spinal cord injury, in order to create a successful design.

\section{Sit and Ski (2010)}

After explaining the physiology of spinal cord injury the students said...."This information will help us to determine how much our sit and ski must support and restrain the athlete... The physiological information also helped us to understand the biomechanics of the movements required to propel a Sit and Ski; allowing us to create a design that will be comfortable yet still light and fast.”

\section{Theme 1. Learning Design: b) Fabrication}

Students look to improve a current design by looking at the strengths and weaknesses of the current design

Universal Play Frame (UPF) Golf (2010)

"Although the UPF has been designed and built five times through Senior Projects, the current frame does not provide for the Friday Club's needs. A redesign is necessary to provide an effective solution.”

Quadricycle (2011)

"I learned that when you're working as a team you need to actually collaborate as a team. So as you are making the geometry of a bike or making some component that's specific you need to know what others are working on have those features in it, so the components all mount systemwise so they work efficiently.”

Foam Wars (2010)

"If it was set up differently and we didn’t spend so much time on design at the beginning of the project we could have had a lot more time for fabrication and then... testing."

\section{Foam Wars (2010)}

"For future students... get as much machining experience as you can in, because we spent too much time working in the lab.”

\section{Theme 1. Learning Design: c) Budgeting}

Clear, early, and consistent messaging regarding budget and funding amounts available to each project were problematic for the students as evidenced by their discussions. This may be deliberate by the engineering faculty as a means to provide the students with the first task of taking an illdefined problem and define it in such a way to solve it [4].

Quadricycle (2011)

"I think that the funds that they gave us initially were not sufficient enough... we went a little over budget and we had to get that cleared.”

\section{UPF Golf (2009)}

"My only suggestion is defining a budget at the beginning and letting us know how much money we have exactly to spend. It was kind of vague in the beginning. They (faculty advisors) were saying, 'design it and it will be okay' and half way through that wasn't the number we were expecting. Just being clear in communication,... because that really influences how we design things and what materials we use.”

Quadricycle (2011)

"It would be nice to know upfront (how much money was available)...like a generalized overview of what it is going to take... I know people when they worked on their project they didn't realize it was almost not like an engineering project, but more like a statistics project or cost analysis type of project, more like see the range of the final project design potential would be nice to know upfront.”

Foam Wars (2010)

"It's kind of engraved in our minds for engineering. It's the same in the real world. You can't just create a product and expect the customer to be like 'oh yeah that's awesome.' You have to go step by step to make sure they (client) are with you throughout the whole process.”

APLV (2009)

"Funding wound up being an issue for us. We wanted to make our launch vehicle motorized and that just simply wasn't an option as well as a few other things due to budget constraints.”

In real-life situations, budget constraints are almost always a barrier in design and production. Although a larger budget was necessary for some of the projects, budget constraints taught the engineering students how to manage and monitor their spending wisely.

\section{Theme 2. Motivation to Complete Design: a) Finishing a Design}

APLV (2009)

"We were able to finish our project on time and see it in action. It was great and extremely rewarding." 
Theme 2. Motivation to Complete Design: b) Working on Real World Design

APLV (2009)

"I think it's been cool to participate in an inter-disciplinary project like this. It gives you a feel for what real-life engineering is like.”

\section{Theme 2. Motivation to Complete Design: c) Completing design from start to finish}

Quadricycle (2011)

"The fact that it was a blank slate from the beginning was a motivation for people even though we all knew that it was going to be incredibly challenging to start building something from scratch. Umm, though,... that and the fact that (client's name) is a student and we can have more access; basically call him up whenever and he'd be around,... not in some other part of the state, you know how other projects are."

Foam Wars (2010)

"That's why I chose the project. By the way it was my first choice. You can see instant gratification out of this.”

\section{Foam Wars (2010)}

"The success of these projects has impacted everyone involved in an extraordinary way, and has expanded the realm of what is possible.”

\section{Theme 3. Perceptions of People with Disabilities: a) Previous experience}

Prior to the project only ten (35\%) had experience working with people with disabilities and of those students the majority were women.

\section{Theme 3. Perceptions of People with Disabilities: b) Changed attitude}

The majority of the team responses centered on "no change of attitude," this was especially evident in groups that had limited time with their client. However, day to day experiences and perceptions may have changed as evidenced by the following discussions.

\section{Quadricycle (2010)}

"The world is set up in a way that makes it most convenient for somebody who has full mobility and a person with a disability might have a little trouble adapting to that so it's necessary to change things a bit... so it would be normal for them I guess... it's kind of a strange way of putting it."

\section{APLV (2009)}

"I have been raised to look past the disability, and see everyone as people. I don't see it as anything extremely significant, I think it's easy to overcome (negative perception) and most people demonstrate that on a daily basis.

Hand Foot Cycle (2009)

"I did not have interactions with people with disabilities before, but now I see things differently. I notice doors and wheelchair ramps. Don't know if it's changed other than that."

\section{UPF Golf (2009)}

"Perception is hard, I mean I didn't really perceive them as any different from like me... but I didn't really know how to talk to them or approach them or if you talk about the disability or if it's something that isn't said, that's not really perception though.”

Quadricycle (2010)

“Mine hasn't really changed either but it's kind of opened my eyes to umm... before it was just that they lacked the ability to do something but now I realize that they gained a lot more of ours, I didn't realize he had such strong upper strength and different ranges or other motions,... and I didn't realize they excel in other places.”

\section{Theme 3. Perceptions of People with Disabilities: c) Changed beliefs}

\section{UPF Golf (2009)}

"On campus you meet students with learning disabilities. It's interesting to see all the adaptations because everyone is so different. What works for one person might not work for someone else. So that's an interesting aspect I've learned from this project.”

Strider (2010)

"It's the same now as when I was a little kid... I was exposed to it. The only thing I learned is that I need to be careful. I may say something without knowing and offend an individual."

\section{APLV (2009)}

"I do (perception of changed beliefs). As much as I've always been taught and believed in equality, I have had feelings of discomfort in the past and getting out there and actually doing it actually helps. It helps you learn the norms and what do when things aren't helpful. Students who worked and interacted with people with disabilities became more comfortable around people with disabilities through "learning by doing."

\section{Theme 4. Planning Stages: a) Etiquette presentation}

Wii-B-Fit (2010)

On importance of workshop and benefit gained:

"Yeah greatly... I guess it kind of changed our perspective in a way. Up until now I never knew how I should interact with people with disabilities.” 
Wii-B-Fit (2010)

"I think through this project and the disability workshop that some of the Kinesiology students put on helped me to be more comfortable with my interaction.”

\section{Theme 5. Improving Future Projects: a) Communication between the Disciplines}

On multidisciplinary work and collaboration between Engineering and Kinesiology students:

Quadricycle (2011)

“We didn't realize they could become involved in a building or designing kind of aspect as much, and so we would say emphasis that is in it's a team. The Kinesiology students can, particularly in the design. We didn't realize maybe it seems obvious but we didn't really take advantage of the knowledge our teammates had till the very end.”

\section{Quadricycle (2011)}

"The projects showed me that you can never get too much clarification on certain things and it's always sort of... you are guessing."

\section{UPF Golf (2009)}

"I think it was unclear from the beginning what the role of the Kinesiology student was. We had to meet with them all the time but what were they actually doing? So maybe a little more background into that; would help the project in regards to the fluidity and everything."

\section{UPF Golf (2009)}

"They (Kinesiology students) kind of validated our design as we went along and said 'hey, it's going to be good' or 'No, why don't you use this?' Sometimes it's kind of nice having an outsider's input rather than just engineering the entire time. They (Kinesiology students) definitely had more exposure to the users than we had. They kind of kept reminding us of things we needed to keep in consideration."

\section{UPF Golf (2009)}

"We all were under the impression (in the beginning) that we were to make one UPF Golf device and it turns out that the sponsors were hoping for two or three for that price. We received full funding but we all were hoping we weren't disappointing our sponsor by delivering one. That kind of miscommunication was kind of bad too, I guess."

Strider (2010)

"It was the middle section of the project where we weren't sure what their role was and they didn't seem sure of what their role was in the building (process). We didn't see much that they could help us with.”

\section{Theme 5. Improving Future Projects: b) Meet client early and often}

Foam Wars (2010)

"I wish we had more time with people with disabilities because then we would be able to cater more and work out the little details maybe next year for whoever takes over.”

\section{Theme 5. Improving Future Projects: c) Clarify expectations and Tasks}

Strider (2010)

"None of us had manufacturing experience and things took longer than expected. Towards the end we felt like they (Kinesiology students) were being pushy and the initial deadlines flew by.”

\section{CONCLUSION}

Clearer expectations and rewards as milestones to be reached need to be established from the onset. This would help avoid situations where students do not know what is expected or how course grading rewards them for being good design engineers. Teamwork, innovation, good project management, productivity, and quality of design must be rewarded [24]. Creating better communication, establishing clearer goals, and increasing awareness of each department's role in the project were some of the collaborative components the engineers addressed in improving the activity design project. However, these experiential projects taught students the importance of organization, time management, communication, and costeffective design plans for real clients. In order to be successful, students had to identify the important issues, conduct research in the area of the project, collaborate with project members, and have effective communication with their client. Our findings support previous findings that client-driven design projects have distinct educational and experiential advantages over professor-driven or studentdriven design projects [25]. Notably by being able to successfully cope with time pressures, cost containment pressures, and pressures of meeting important specifications through brainstorming alternative designs, testing and negotiating [25]. Although actual perceptions of people with disabilities did not change due to limited exposure to clients, overall findings are comparable to other studies which report refinement of engineering skill, self confidence, altruism, and contribution to society [26-27]. Previous research underscores the importance of having two professions working on the same problem to maximize client functionality from divergent viewpoints [28]. Collaborative solutions are possible by a "learn by doing" approach.

\section{ACKNOWLEDGMeNT}

This research was made possible through the National Science Foundation (Grant DUE-1062297). Any opinions, findings, and conclusions or recommendations expressed in this material are those of the author and do not necessarily reflect the views of the funding agency. 


\section{REFERENCES}

[1] Lekhakul, S. and Higgins, R. "Senior design project: Undergraduate thesis,” IEEE Trans. Educ., Vol. 37, No. 2, May 1994, pp. 206-230.

[2] Selfridge, R.H., Schultz, S.M., and Hawkins, A.R. "Free-Space optical link as a model undergraduate design project," IEEE Trans. Educ., Vol. 50, No. 3, August 2007, pp. 208-215.

[3] Criteria for Accrediting Engineering Programs ABET Engineering Accreditation Commission, April 1, 2011 [Online]. Available: http://www.abet.org

[4] Bohnmann, L.J., Mork, B.A., and Wiitanen, D.O. "Power engineering design projects versus topical design courses," IEEE Transactions on Power Systems, Vol. 19, No. 1, February 2004, pp. 152-156.

[5] Shannon, C., Schoen, B., and Tansey, T. "The effect of context, content, and social power on undergraduate attitudes toward persons with disabilities”. Journal of Rehabilitation, Vol., 75, No. 4, 2009, pp. 11-18.

[6] Lehoux, P., Poland B. and Daudelin, G. "Focus group research and the patient's view". Social Science and Medicine, Vol., 63, 2006, pp. 2091- 2104.

[7] Edmunds, H. The Focus Group Research Handbook. Chicago: NTC Business Books and the American Marketing Association. 1999.

[8] Borrego, M., Douglass, E.P., and Amelink, C.T. "Quantitative, qualitative, and mixed research methods in engineering education." Journal of Engineering Education, Vol. 98, No. 1, 2009, pp. 53-66.

[9] Koro-Ljungberg, M. and Douglass, E.P. "State of qualitative research in engineering education: Meta-analysis of JEE articles, 2005-2006." Journal of Engineering Education, Vol. 97, No. 2, 2008, pp. 163-175.

[10] Leydens, J.A., Moskal, B.M., and Pavelich, M.J. "Qualitative methods used in the assessment of engineering education." Journal of Engineering Education, Vol. 93, No. 1, 2004, pp. 65-72.

[11] Gilmore, G and Campbell, M. Needs and Capacity Assessment Strategies for Health Education and Health Promotion ( $3^{\text {rd }}$ edition). Sudbury, MA: Jones and Bartlett Publishers, 2005, pp. 98.

[12] Krueger R., and Casey M. Focus Groups: a Practical Guide for Applied Research. Thousand Oaks, CA: Sage Publications. 2000.

[13] Cottrell, R, and McKenzie, J. In Health Promotion and Education Research Methods: Using the five-chapter thesis/dissertation model. "Qualitative Research Methods: Writing Chapter III.” 2005, pp. 228.

[14] Guba E. and Lincoln Y. Fourth generation evaluation, 1989, Newbury Park, CA: Sage.

[15] Sim, J. "Collecting and analyzing qualitative data: issues raised by the focus group.” Journal of Advanced Nursing, Vol. 28, No. 2, 1998, pp. 345-352.

[16] Kotarba, J. "The team concept in qualitative research with illicit drug users." Substance Use \& Misuse, Vol. 45, No. 5, 2010, pp. 787-788.

[17] Rabiee, F. "Focus-group interview and data analysis." Proceedings of the Nutrition Society, Vol. 63, No. 4, 2004, pp. 655-660.

[18] Patton M. Qualitative Research and Evaluation Methods, 3rd edition. Newbury Park: Sage. 2002.

[19] Lacey, A., and Luff, D. Focus for Research and Development in Primary Health care: an Introduction to Qualitative Analysis. Trent Focus Publishers, 2001.

[20] Mays, N., and Pope C. Assessing quality in qualitative research. British Medical Journal Vol. 320, 2000, pp. 50-52.

[21] Strauss, A. and Corbin J. Basics of qualitative research: grounded theory procedures and techniques. 1990, Newbury Park, CA: Sage.

[22] Barbour R. "Checklists for improving rigor in qualitative research: A case of the tail wagging the dog?” British Medical Journal Vol. 322, 2001, pp. 1115-1117.

[23] Lombard, M., Snyder-Duch, J., and Campanella Bracken, C. (Oct. 2004). Report: Inter-coder Reliability in Content Analysis: Practical Resources for Assessing and Reporting Inter-coder Reliability in Content Analysis Research Projects. June 21, 2010, [Online]. Available: http://www.temple.edu/sct/mmc/reliability/

[24] Loendorf, W., Richter, D., and Teachman, D. "Results from an interdisciplinary service learning pilot project incorporating Universal design concepts for ADA compliance." American Society for Engineering Education, ASEE Annual Conference Presentation in Washington D.C., 2010.
[25] Ansell, H. "Professor-driven, student-driven, and client-driven design projects," Proceedings of 1998 Frontiers in Education Conference, 1998, Tempe, Arizona, Session T2D.

[26] Blanchard, S. and Rohrbach, R. "Capstone engineering design projects to aid disabled persons," Annual International

Conference of the IEEE Engineering in Medicine and Biology Proceedings, Vol. 4, 2000, pp. 2942-2944.

[27] Blood, D., Koch, B., Ballun, M., Budnik, M., and Duncan, G.S. “A Braille Press Project: Improving the literacy of the world's visually impaired," International Journal for Service Learning in Engineeering, Vol. 5, No 2, (2010), pp. 1-16.

[28] Mikolajewska, E. and Mikolajewska, D. "Wheelchair development from the perspective of physical therapists and biomedical engineers," Advances in Clinical and Experimental Medicine, Vol. 19, No. 6, 2010, pp. 771-776. 